\title{
How feasible are healthy eating and physical activity for young women?
}

\author{
Kylie Ball* , David Crawford and Narelle Warren \\ School of Health Sciences, Deakin University, 221 Burwood Highway, Burwood, Victoria 3125, Australia
}

Submitted 16 June 2003: Accepted 3 September 2003

\begin{abstract}
Objective: This study investigated young women's perceptions of the feasibility of physical activity and healthy eating behaviours, and how these vary by socioeconomic status, domestic characteristics and weight status.

Design: This population-based study used a mailed questionnaire to investigate perceptions of the feasibility of commonly recommended healthy eating and physical activity behaviours among a sample of young women. The feasibility of 29 physical activity behaviours (e.g. relating to frequency, intensity, duration, domain/setting) and 15 healthy eating behaviours (e.g. relating to location/setting, fruit and vegetable intake, fat/sugar intake) was assessed. Height, weight and sociodemographic details were also obtained.

Setting: Nation-wide community-based survey.

Subjects: A total of 445 women aged 18-32 years selected randomly from the Australian electoral roll.

Results: Most women reported that they either were already engaged in many of the healthy eating behaviours or saw these as highly feasible. Many physical activity behaviours, on the other hand, were perceived as less feasible, particularly among women with children and women who were overweight.

Conclusions: Health promotion messages and strategies aimed at increasing physical activity and healthy eating are unlikely to succeed unless they take into account perceptions that these behaviours are not feasible. For young women, this may involve promoting more time-effective, flexible ways of achieving recommended physical activity. Messages specifically targeted to women with children, and women who are overweight, are required.
\end{abstract}

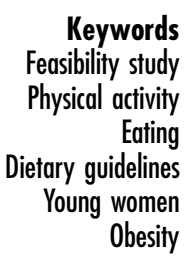

Young adult women are at high risk of weight gain, of becoming obese and of developing obesity-related conditions over time. For example, longitudinal data from the USA demonstrate that, over a 10-year period, women had twice the risk of major weight gain as men, with the greatest weight gain observed for women in their twenties and thirties ${ }^{1}$. In the first published longitudinal study to report weight change data for an Australian population sample, Ball et $a .^{2}$ demonstrated that weight gain over a 4-year study period (1996-2000) was common among young women, with $41 \%$ of $18-23$-year-olds gaining weight ( $>5 \%$ increase in body mass index (BMI)) over this time. This epidemic of weight gain among young women is likely to have a substantial impact on their risk of morbidity and mortality from a number of chronic health conditions. For instance, in the USA, more women than men have died of cardiovascular disease (CVD), a condition for which obesity is a key risk factor, every year in the last 15 years ${ }^{3}$.

Women's heightened risks of weight gain, obesity and associated ill-health are likely to be at least partly attributable to behavioural factors. Physical inactivity and poor diet are two major risk factors for weight gain, CVD and other chronic conditions ${ }^{4,5}$. Consistent with international findings ${ }^{4,6}$, recent population data show that Australian women are less likely to exercise regularly than are men $^{7}$, and that physical activity levels decline rapidly in young adult women between the ages of 18 and 29 years ${ }^{8}$. Young women are also high consumers of takeaway foods, which are often energy-dense, high in fat and believed to contribute significantly to increased energy intake and possibly to increases in obesity ${ }^{2,9,10}$. Recent analyses of population data in Australia showed that almost $50 \%$ of $18-23$-year-old women reported eating take-away food once a week or more, and this was associated with increased risk of weight gain ${ }^{2}$.

Recognising the significant threat to population health posed by the current obesity epidemic, and by widespread physical inactivity and poor dietary habits, health authorities in many countries have developed guidelines aimed at encouraging the public to change their physical activity and eating habits. For example, in Australia, a 
national strategic plan for the prevention of obesity has been developed ${ }^{11}$. That plan focuses on encouraging and supporting individuals to control their weight, through incorporating regular moderate- and vigorousintensity physical activity into their lifestyles, and reducing their fat and energy intakes. These recommendations are generally consistent with those included in Australian Dietary Guidelines ${ }^{12}$ and National Physical Activity Guidelines $^{13}$.

In many developed countries, the public is exposed to a plethora of information based on official health recommendations regarding nutrition, physical activity and weight control (e.g. references 12-15). However, the increasing prevalence of weight gain and obesity highlights the lack of effectiveness of such recommendations in preventing weight gain. It is therefore important to ask why activity levels remain low, why dietary patterns are less than desirable and why obesity continues to increase. It has been suggested that the types of strategy that have been promoted by health authorities may not be feasible for or salient to individuals in the context of their daily lives ${ }^{16}$. However, to date, public perceptions of the feasibility of adopting weight-gain prevention strategies have not been examined. Investigation of the perceived feasibility of recommended physical activity and dietary habits may shed light on the apparent lack of success in achieving behavioural change. This is particularly important among groups at high risk of weight gain, including young women.

The perceived feasibility of specific physical activity and dietary behaviours is likely to be influenced by a number of key personal, social, environmental and life-stage contexts that are important influences on young women's lives. In a recent review of behaviour change interventions aimed at improving women's cardiovascular health, Krummel et al. $^{17}$ highlighted the lack of information available to guide effective physical activity and dietary interventions, and developed a set of research recommendations for interventions targeting physical activity and dietary change in women. For both behaviours, a key recommendation was the tailoring of interventions to the stage of the life cycle. Young women's risk of weight gain, physical inactivity and poor diet may be related to a number of key life events common to this life stage ${ }^{18}$. In particular, changes in young women's domestic situation as they leave the family home, enter a de facto partnership or marriage, or have children are likely to have a major influence on their ability to adopt or adhere to healthy behaviours ${ }^{2,19-24}$. It has also been recommended that interventions targeting women's health behaviours should be tailored to specific subgroups (e.g. socio-economically disadvantaged, obese women), whose particular needs have often not been considered ${ }^{17}$. A large body of evidence demonstrates that individuals of lower socioeconomic status (SES) have poorer health behaviours, and are at higher risk of obesity, than those of higher status $^{25,26}$. Whether this is due to SES differences in the perceived feasibility of making changes in physical activity and healthy eating behaviours requires investigation. Similarly, few studies have investigated the particular difficulties in making these lifestyle changes among women who are already overweight. In a populationbased study, Ball et $a l^{2}$ found that almost one in four overweight adults reported being overweight as a key barrier to them being physically active. With such a large and increasing proportion of young women already carrying excess weight, an examination of the feasibility of adhering to recommended physical activity and dietary guidelines among those already overweight is timely.

It is important to determine how factors such as SES, domestic situation and overweight status might influence women's perceptions of the feasibility of incorporating recommendations regarding physical activity and dietary habits into their lives. The present study investigated women's perceptions of the feasibility of a number of specific physical activity and dietary strategies, and how these vary by SES, domestic situation and weight status.

\section{Methods}

\section{Procedure}

The study was approved by the Deakin University Human Research Ethics Committee. A questionnaire was developed and pilot-tested with women in the same age group as participants, and minor revisions for clarification were made. The questionnaire was then posted to women with a letter describing the study and inviting them to participate; a consent form for participation; and a replypaid envelope for returns. A reminder postcard was sent to non-respondents 2 weeks later, and a second reminder with replacement questionnaire was sent a further 3 weeks later.

\section{Participants}

A total of 462 women aged 18-32 years participated in this study. This represented a response rate of $41 \%$ (excluding those who had moved and left no forwarding address) among a sample of 1200 women selected from the Australian Electoral Roll using a stratified random sampling procedure, with strata based on the number of eligible cases in each of the eight States/Territories of Australia. Voting is compulsory for Australian adults and hence the electoral roll provides a complete record of population data on Australian residents aged 18 years and over. This response rate is comparable to those reported in similar postal studies with this age group ${ }^{27,28}$.

\section{Measures}

The questionnaire completed by the participants included questions on the following issues. 


\section{Sociodemographic background}

Sociodemographic details included education level (highest level of schooling: still at school, primary school, some high school, completed high school, technical/trade school certificate/apprenticeship or university/tertiary qualification), which was subsequently categorised as tertiary-educated or not tertiary-educated and used as an indicator of SES. These two broad categories of education were used since the proportions of women in several of the individual categories were very small and hence these categories had to be collapsed. Questions on marital status and parity (number of children) were also included. Domestic situation (household composition) was assessed by asking 'Who lives with you?', with response options noone, I live alone; partner/spouse; own children; someone else's children; parents; brothers/sisters; other adult relatives; and other adults who are not family members. This was subsequently re-categorised as living with parental family; living alone/share 'flatting'; living with partner (no children); or living with children (including those living with partner and child(ren) and single mothers).

\section{Body weight}

Participants were asked to self-report their height and weight, which were used to calculate BMI (as weight $(\mathrm{kg})$ divided by square of height $\left(\mathrm{m}^{2}\right)$ ). Self-reported height and weight have previously been shown to provide a reasonably valid measure of actual height and weight for the purpose of investigating relationships in epidemiological studies ${ }^{29}$. For the purpose of analysis, women were classified as overweight (BMI $>25 \mathrm{~kg} \mathrm{~m}^{-2}$ ) or not overweight $\left(\mathrm{BMI} \leq 25 \mathrm{~kg} \mathrm{~m}^{-2}\right)^{30}$.

\section{Feasibility of adopting physical activity and dietary behaviours}

The feasibility of adopting 29 physical activity behaviours and 15 eating behaviours was assessed by asking participants: 'How feasible is it for you to do the following?' The complete list of feasibility items is included in the Appendix. These 44 items were based on recommendations included in the Australian Dietary Guidelines and the National Physical Activity Guidelines, and information arising from them that has been promoted to the public ${ }^{12,13}$.

Of the physical activity behaviours, three were related to frequency (1-2 times/week, 3-4 times/week, 5 or more times/week); three to intensity (walking, moderate and vigorous leisure-time activity); three to duration (10 min, $30 \mathrm{~min},>30 \mathrm{~min}$ ); five to incidental activity (walk or cycle to work/place of study; walk or cycle to shops; park car further away from work/place of study and walk; get off the train/bus a stop earlier and walk; take stairs instead of the lift); four to the setting (around your home/garden; in your own neighbourhood; at work/place of study; on your way to work/place of study); five to time of the day or week (before starting the day's activities; during the day's activities; at the end of the day's activities; on weekdays; on weekends); three to social support (on own; with partner/family; with friends/work-mates); and three to the domain (leisure-time, work, sport/gym).

Of the 15 eating behaviours, three related to setting (at home; at work/place of study; out for a meal); two to fruit and vegetable intake (at least two pieces of fruit most days; at least five servings of vegetables most days); five to restricting fat/sugar intake (pastries/cakes/chocolates/biscuits; takeaways; fried foods; margarine; sugar in tea/coffee); four to choosing low-fat or low-calorie products/cooking methods (reduced-fat dairy products; lean meat; low-joule soft drinks; low-fat cooking methods); and one to restricting alcohol intake (two drinks or less a day).

Response options for all feasibility questions were: I already do this; I don't do this but it definitely is feasible; I don't do this but it might be feasible; I don't do this and it's definitely not feasible; and doesn't apply to me. For analyses, the final response 'Doesn't apply to me' was recoded where appropriate (in nine items) as either 'I don't do this and it's definitely not feasible' or 'I already do this'. For example, doesn't apply responses for items involving physical activity at work/place of study were re-coded as 'I don't do this and it's definitely not feasible', since a large proportion of the women reported not currently working/studying. For two eating behaviours, 'Keep to two drinks or less of alcohol a day?' and 'Avoid adding sugar to tea or coffee?', 'Doesn't apply to me' was re-coded as 'I already do this'. For all other items, data from the small proportion of women who reported doesn't apply for any item were excluded from analyses involving that particular item.

\section{Making physical activity and bealthy eating easier}

Participants were also asked: 'What is the single most important thing that you could do, or that could be done, to make it easier for you to be physically active?' They were also asked: "What is the single most important thing that you could do, or that could be done, to make it easier for you to eat a healthy diet?' These were open-ended questions.

\section{Statistical analyses}

Analyses were conducted using SPSS version 11.0.0 statistical software $^{31}$. Initially, descriptive analyses investigated the percentages of women reporting different levels of perceived feasibility of adopting physical activity and eating behaviours. Content analyses of the openended questions regarding the most important things that could be done to make it easier to be physically active and to eat a healthier diet were undertaken to identify the main recurring themes.

Exploratory factor analysis using SPSS FACTOR was then performed on the 44 feasibility items, to identify 
underlying patterns of relationships among individual items and reduce the feasibility items to facilitate subsequent analyses. Principal components analysis with varimax rotation (since factors were not correlated) was used. Items that cross-loaded on several factors (i.e. items that had a loading of $>0.4$ on more than one factor), and items that had a loading of $<0.4$ on all factors, were subsequently eliminated. Inter-item reliability for each factor was assessed by Cronbach's $\alpha$ coefficients. Kaiser's measure of sampling adequacy was used to confirm the appropriateness of factor analysis ${ }^{32}$.

Analysis of variance or $t$-tests were then performed separately for each of the standardised factor scores to investigate differences in perceived feasibility between those in the four different domestic situation categories; between those of higher and lower SES; and between women who were overweight and those who were not.

\section{Results}

\section{Profile of participants}

Sociodemographic characteristics of the sample are presented in Table 1. A large proportion (42\%) of the respondents were tertiary-educated, just over half were either married or living in a de facto relationship, and almost a third had at least one child. The median age was 26 (standard deviation 4.4) years. The mean BMI was $24.1 \mathrm{~kg} \mathrm{~m}^{-2}$, with almost a third of the women classified as overweight or obese. Examination of the sociodemographic profile of the sample compared with that of

Table 1 Sociodemographic and weight characteristics of the sample $(n=445)$

\begin{tabular}{|c|c|}
\hline Characteristic & $\%$ of sample \\
\hline Mean age (years) & 25.7 \\
\hline \multicolumn{2}{|l|}{ Age (years) } \\
\hline $18-22$ & 30 \\
\hline $23-27$ & 29 \\
\hline $28-32$ & 41 \\
\hline \multicolumn{2}{|l|}{ Education } \\
\hline Tertiary educated & 42 \\
\hline Not tertiary educated & 58 \\
\hline \multicolumn{2}{|l|}{ Domestic situation } \\
\hline Living with parental family & 29 \\
\hline Living alone/share 'flatting' & 18 \\
\hline Living with partner, no children & 24 \\
\hline Living with children & 29 \\
\hline \multicolumn{2}{|l|}{ Marital status } \\
\hline Married/de facto/separated/widowed/divorced & 53 \\
\hline Never married & 47 \\
\hline \multicolumn{2}{|l|}{ Number of children } \\
\hline None & 70 \\
\hline One child & 12 \\
\hline Two or more children & 18 \\
\hline Mean BMI $\left(\mathrm{kg} \mathrm{m}^{-2}\right)$ & 24.1 \\
\hline \multicolumn{2}{|l|}{ BMI category } \\
\hline Underweight & 18 \\
\hline Healthy weight & 51 \\
\hline Overweight & 17 \\
\hline Obese & 14 \\
\hline
\end{tabular}

$\mathrm{BMI}$ - body mass index. women of similar age (18-44 years) who participated in the most recent (2001) Australian National Health Survey $(\mathrm{NHS})^{33}$ showed that the present sample was reasonably similar to that population in terms of marital status and income level. There were a slightly higher proportions in the present sample of Australian-born women (89\% vs. 83\% among 18-24-year-olds and 74\% among 25-44-yearolds in the NHS) and of women not in the labour force ( $28 \%$ vs. $21 \%$ and $27 \%$, respectively); and a slightly lower proportion of women with tertiary qualifications ( $42 \%$ vs. $53 \%$ and $61 \%$, respectively).

\section{Feasibility of physical activity and dietary behaviours}

The perceived feasibility of various physical activity behaviours is presented in Table 2. The majority (70\%) of women reported they were already physically active once or twice a week, and none of them felt it was definitely not feasible to be active this often. Conversely, only one in four women reported they were active five or more times a week, and one in four believed it was definitely not feasible for them to be active this frequently.

A range of physical activity behaviours was perceived as definitely not feasible by a large proportion of the women. These included most of the active transport options (walking or cycling to work, parking the car and walking the extra distance, getting off the train or bus a stop earlier and walking, or being physically active on the way to work), the use of stairs instead of the lift and physical activity in or around their place of work or study. Apart from these, a majority of the women indicated that the other physical activity behaviours were feasible, to varying extents.

Overall, half or more of the women reported they already engaged in many healthy eating behaviours and habits (Table 3). Where they did not currently practise these, most women in this sample indicated that the eating behaviours were either possibly or definitely feasible. Unlike the physical activity behaviours, few participants indicated that any of the healthy eating behaviours were definitely not feasible.

\section{Factor analysis of perceived feasibility of physical activity and dietary bebaviours}

The factor analysis led to the deletion of five items due to cross-loading (vigorous physical activity; physical activity around your neighbourhood; physical activity before day's activities; eat healthy at home; restrict alcohol intake) and one item (physical activity with partner/family) due to low loading on all factors. The resultant analysis revealed eight distinct, interpretable factors (shown in Tables 2 and 3). The Cronbach's $\alpha$ coefficients for the eight factors ranged from 0.54 to 0.93 , indicating moderate to excellent internal reliability. Together the eight factors explained $57 \%$ of the total variance. 
Table 2 Perceived feasibility of physical activity behaviours $(n=445)$ (factor loadings $>0.4$ are shown)

\begin{tabular}{|c|c|c|c|c|c|}
\hline Feasibility of physical activity behaviour & $\begin{array}{l}\text { Factor } \\
\text { loading }\end{array}$ & $\begin{array}{l}\text { Definitely not } \\
\text { feasible (\%) }\end{array}$ & $\begin{array}{c}\text { Might be } \\
\text { feasible (\%) }\end{array}$ & $\begin{array}{l}\text { Definitely is } \\
\text { feasible (\%) }\end{array}$ & $\begin{array}{c}\text { Already } \\
\text { do this (\%) }\end{array}$ \\
\hline \multicolumn{6}{|l|}{$\begin{array}{l}\text { Factor 1: Leisure-time physical activity } \\
\text { Eigenvalue: } 8.94 \\
\text { Explained variance: } 23.5 \% \\
\text { Cronbach's alpha: } 0.93\end{array}$} \\
\hline Be physically active $1-2$ times/week & 0.80 & 0 & 11 & 19 & 70 \\
\hline Be physically active $3-4$ times/week & 0.78 & 8 & 23 & 24 & 45 \\
\hline Be physically active 5 or more times/week & 0.68 & 26 & 27 & 23 & 24 \\
\hline Spend $10 \mathrm{~min}$ at a time being active & 0.77 & 0 & 5 & 27 & 68 \\
\hline Spend $30 \mathrm{~min}$ at a time being active & 0.82 & 1 & 14 & 26 & 58 \\
\hline Spend more than $30 \mathrm{~min}$ at a time being active & 0.79 & 7 & 19 & 28 & 47 \\
\hline Be physically active at end of day's activities & 0.63 & 12 & 22 & 27 & 40 \\
\hline Be physically active on weekdays & 0.81 & 3 & 14 & 19 & 65 \\
\hline Be physically active on weekends & 0.68 & 3 & 12 & 29 & 56 \\
\hline Be physically active on your own & 0.68 & 3 & 8 & 22 & 67 \\
\hline Be physically active with friends/work-mates & 0.56 & 12 & 25 & 27 & 37 \\
\hline Be physically active in leisure or free time & 0.72 & 1 & 10 & 27 & 63 \\
\hline Play sport, or attend a gym or fitness centre & 0.52 & 13 & 19 & 26 & 43 \\
\hline Go for a walk to get exercise & 0.50 & 1 & 5 & 29 & 65 \\
\hline Do moderate kinds of activities & 0.49 & 7 & 24 & 36 & 33 \\
\hline \multicolumn{6}{|l|}{$\begin{array}{l}\text { Factor 2: Work/domestic physical activity } \\
\text { Eigenvalue: } 3.16 \\
\text { Explained variance: } 8.3 \% \\
\text { Cronbach's alpha: } 0.73\end{array}$} \\
\hline Be physically active as part of work or other activities & 0.82 & 24 & 17 & 17 & 43 \\
\hline Be physically active during day's activities & 0.80 & 17 & 21 & 17 & 45 \\
\hline Be physically active at work/place of study & 0.77 & 41 & 13 & 11 & 35 \\
\hline Be physically active around home or garden & 0.43 & 2 & 14 & 23 & 61 \\
\hline \multicolumn{6}{|l|}{$\begin{array}{l}\text { Factor 4: Physical activity for transport } \\
\text { Eigenvalue: } 2.07 \\
\text { Explained variance: } 5.4 \% \\
\text { Cronbach's alpha: } 0.72\end{array}$} \\
\hline Be physically active on way to work/place of study & 0.81 & 52 & 12 & 15 & 20 \\
\hline Walk/cycle to work/place of study instead of driving & 0.72 & 60 & 10 & 11 & 19 \\
\hline Get off train/bus a stop earlier and walk & 0.72 & 70 & 10 & 11 & 9 \\
\hline Walk/cycle instead of drive to local shops & 0.43 & 15 & 12 & 27 & 37 \\
\hline \multicolumn{6}{|l|}{$\begin{array}{l}\text { Factor 7: Incidental physical activity } \\
\text { Eigenvalue: } 1.25 \\
\text { Explained variance: } 3.3 \% \\
\text { Cronbach's alpha: } 0.56\end{array}$} \\
\hline Park car and walk the extra distance & 0.54 & 56 & 13 & 18 & 14 \\
\hline Take stairs instead of lift & 0.62 & 41 & 18 & 5 & 36 \\
\hline \multicolumn{6}{|l|}{ Items not loading on any factor } \\
\hline Do vigorous kinds of activities & - & 13 & 25 & 26 & 36 \\
\hline Be physically active in neighbourhood or suburb & - & 7 & 19 & 33 & 41 \\
\hline Be physically active before day's activities & - & 19 & 22 & 33 & 26 \\
\hline Be physically active with partner/family & - & 7 & 19 & 30 & 44 \\
\hline
\end{tabular}

Provisional names were assigned to the eight factors and standardised factor scores were computed for each factor. Mean standardised factor scores are presented in Table 4 (a higher score representing a higher level of perceived feasibility for items loading on that factor).

Analysis of variance showed that mean scores differed significantly by domestic situation for the following factors: leisure-time physical activity; work/domestic physical activity; physical activity for transport; incidental physical activity; and fruit and vegetables (see Table 4). Women with children perceived leisure-time physical activity and physical activity for transport as less feasible, whilst women living alone or in a shared house perceived these physical activities as more feasible. Women with children also perceived incidental physical activity as less feasible for them, yet perceived work/domestic physical activity as more feasible. They also perceived fruit and vegetable consumption as more feasible, whereas women living along or in a shared house perceived this as less feasible for them.

$t$-Tests showed that mean scores differed by weight status for three of the factors (see Table 4). Overweight women tended to perceive leisure-time physical activity and physical activity for transport as less feasible than did women who were not overweight. Conversely, consumption of reduced-energy/fat drinks and condiments was reported as being more feasible for overweight women than others. There were no significant differences in mean factor scores by SES (education) for any of the eight factors (data not shown). 
Table 3 Perceived feasibility of eating behaviours $(n=445)$ (factor loadings $>0.4$ are shown)

\begin{tabular}{|c|c|c|c|c|c|}
\hline Feasibility of eating behaviour & $\begin{array}{l}\text { Factor } \\
\text { loading }\end{array}$ & $\begin{array}{l}\text { Definitely not } \\
\text { feasible (\%) }\end{array}$ & $\begin{array}{c}\text { Might be } \\
\text { feasible (\%) }\end{array}$ & $\begin{array}{l}\text { Definitely is } \\
\text { feasible (\%) }\end{array}$ & $\begin{array}{c}\text { Already } \\
\text { do this (\%) }\end{array}$ \\
\hline \multicolumn{6}{|l|}{$\begin{array}{l}\text { Factor 3: Eating out/high-fat prepared foods } \\
\text { Eigenvalue: } 2.30 \\
\text { Explained variance: } 6.0 \% \\
\text { Cronbach's alpha: } 0.67\end{array}$} \\
\hline Restrict eating pastries, cakes, etc. to once a week or less & 0.74 & 7 & 10 & 42 & 41 \\
\hline Restrict takeaways to once a week or less & 0.73 & 1 & 9 & 20 & 71 \\
\hline Avoid fried foods & 0.69 & 3 & 11 & 33 & 54 \\
\hline Eat healthy when go out for a meal & 0.47 & 1 & 15 & 36 & 48 \\
\hline \multicolumn{6}{|l|}{$\begin{array}{l}\text { Factor 5: Reduced-energy/fat drinks or condiments } \\
\text { Eigenvalue: } 1.44 \\
\text { Explained variance: } 3.8 \% \\
\text { Cronbach's alpha: } 0.64\end{array}$} \\
\hline Drink low-joule or diet soft drinks & 0.71 & 12 & 8 & 31 & 49 \\
\hline Eat reduced-fat or skimmed milk & 0.66 & 8 & 7 & 20 & 65 \\
\hline Avoid adding sugar to tea or coffee & 0.64 & 12 & 11 & 25 & 52 \\
\hline Eat a scrape of margarine & 0.47 & 2 & 6 & 28 & 64 \\
\hline \multicolumn{6}{|l|}{$\begin{array}{l}\text { Factor 6: Low-fat cooking } \\
\text { Eigenvalue: } 1.35 \\
\text { Explained variance: } 3.6 \% \\
\text { Cronbach's alpha: } 0.71\end{array}$} \\
\hline Use low-fat cooking methods & 0.79 & 2 & 6 & 14 & 78 \\
\hline Eat lean meat/poultry, trimmed fat & 0.79 & 2 & 4 & 15 & 80 \\
\hline \multicolumn{6}{|l|}{$\begin{array}{l}\text { Factor 8: Fruit and vegetables } \\
\text { Eigenvalue: } 1.12 \\
\text { Explained variance: } 2.9 \% \\
\text { Cronbach's alpha: } 0.54\end{array}$} \\
\hline Eat two pieces of fruit most days & 0.74 & 2 & 7 & 43 & 48 \\
\hline Eat five servings of vegetables most days & 0.73 & 5 & 15 & 39 & 41 \\
\hline \multicolumn{6}{|l|}{ Items not loading on any factor } \\
\hline Eat healthy at home & - & 1 & 4 & 26 & 69 \\
\hline Eat healthy at work/place of study & - & 12 & 8 & 25 & 55 \\
\hline Keep to two drinks or less of alcohol a day & - & 2 & 4 & 7 & 87 \\
\hline
\end{tabular}

Table 4 Mean standardised feasibility factor scores by domestic situation and weight status

\begin{tabular}{|c|c|c|c|c|c|c|c|c|c|}
\hline \multirow[b]{2}{*}{ Factor } & \multirow[b]{2}{*}{ Total sample } & \multicolumn{5}{|c|}{ Domestic situation } & \multicolumn{3}{|c|}{ Weight status } \\
\hline & & Parents & Alone/share & Partner & Children & $P$-value* & Not overweight & Overweight & $P$-value $\dagger$ \\
\hline $\begin{array}{l}\text { F1: Leisure-time } \\
\text { physical activity }\end{array}$ & 0.00 & 0.16 & 0.27 & -0.04 & -0.36 & $<0.01$ & 0.15 & -0.20 & 0.02 \\
\hline $\begin{array}{l}\text { F2: Work/domestic } \\
\text { physical activity }\end{array}$ & 0.07 & -0.04 & -0.14 & -0.17 & 0.31 & 0.03 & -0.14 & 0.03 & 0.79 \\
\hline $\begin{array}{l}\text { F3: Eating out/high-fat } \\
\text { prepared foods }\end{array}$ & 0.02 & -0.10 & -0.05 & 0.06 & 0.08 & 0.69 & 0.02 & -0.10 & 0.39 \\
\hline $\begin{array}{l}\text { F4: Physical activity } \\
\text { for transport }\end{array}$ & 0.02 & 0.04 & 0.37 & -0.04 & -0.35 & $<0.01$ & 0.06 & -0.21 & 0.04 \\
\hline $\begin{array}{l}\text { F5: Reduced-energy/fat } \\
\text { drinks or condiments }\end{array}$ & 0.01 & 0.15 & 0.23 & -0.13 & -0.18 & 0.06 & 0.10 & 0.21 & 0.03 \\
\hline F6: Low-fat cooking & -0.04 & -0.16 & -0.04 & 0.03 & 0.16 & 0.32 & -0.01 & 0.04 & 0.75 \\
\hline F7: Incidental physical activity & -0.14 & 0.08 & -0.03 & 0.23 & -0.35 & $<0.01$ & 0.10 & -0.15 & 0.12 \\
\hline F8: Fruit and vegetables & 0.10 & 0.01 & -0.28 & 0.08 & 0.24 & 0.05 & -0.05 & 0.07 & 0.35 \\
\hline
\end{tabular}

${ }^{*} P$-value for analysis of variance/t-tests of significance of differences between women in four domestic situation categories.

$\dagger P$-value for $t$-tests of significance of differences between overweight and not overweight women.

\section{Making physical activity and bealtby eating easier}

Women identified a number of things that could be done to make it easier for them to participate in physical activity. The most common responses were: better time management/making more time for exercise (23.1\%); increased motivation (17.5\%); reducing or altering work/study hours (10.2\%); having inexpensive child support or having a child in school (9.6\%); increasing walking (9.4\%); and joining a gym (8.4\%). With regard to what would help with eating a healthy diet, women most often mentioned: having more time to prepare healthy foods (10.8\%); having more fresh and healthy food in the house (10.7\%); having tasty, healthy food alternatives available (9.0\%); greater motivation and self-control (9\%); limiting sugar and confectionery (9.0\%); and eating more fruits and vegetables (8.3\%). 


\section{Discussion}

In order to increase population physical activity levels and improve eating habits, it is important that health authorities take into account how feasible it is for individuals to incorporate into their daily lives the kind of behavioural changes that are being promoted. Health promotion messages and intervention strategies aimed at increasing physical activity and healthy eating are unlikely to succeed unless they address perceptions that these behaviours are not feasible. The findings of this study, which focused on a target group at high risk of weight gain, suggest that typically recommended healthy eating behaviours were on the whole considered feasible, with many young women reporting that they already ate healthily at home, used low-fat products and cooking methods, and otherwise adhered to recommendations for healthy eating. For those women who were not already doing so, most eating behaviours were viewed as highly feasible. Achieving optimum physical activity levels, on the other hand, may be difficult, since a number of recommended behavioural changes were perceived by women to be simply not feasible. For example, 'active transport' strategies that have been promoted as ways to increase overall activity levels ${ }^{13}$ were seen as definitely not feasible by more than one in two women. This clearly suggests that physical activity messages being promoted to young women may need to be revised to better address their views of the feasibility of change.

The physical activity guidelines for Australians recommend that adults accumulate $30 \mathrm{~min}$ of moderateintensity activity at least 5 days per week ${ }^{13}$. The findings that the majority of participants indicated it was feasible for them to incorporate moderate-intensity activities into their lifestyles, and that they could find time to spend at least $30 \mathrm{~min}$ per day being active, are encouraging. However, it is of concern that one in four women felt it was definitely not feasible for them to be active five times a week. Advice on how to incorporate this amount of physical activity into their day may help more women see this recommendation as achievable. The suggestion, for instance, of breaking down $30 \mathrm{~min}$ to $10 \mathrm{~min}$ three times daily is currently incorporated into Australia's physical activity guidelines, but may need stronger emphasis. Efforts to promote this level of activity could focus particularly on increasing activity in the home or local neighbourhood, as women generally saw activity in these settings as more feasible.

In promoting recommendations for improving physical activity and eating behaviours, health authorities have largely promoted 'one size fits all' strategies intended for the whole population. The data presented here suggest that individual circumstances relating to domestic situation and weight status may have important influences on how achievable such strategies are perceived to be. Specifically, women with children were less likely than were other women to see many leisure-time physical activity behaviours as being feasible. The findings, consistent with past studies investigating barriers among women ${ }^{34-36}$, support the recommendation that interventions aimed at women should be tailored to this stage of the life cycle ${ }^{17}$. Policy-makers may thus need to explore opportunities to create more supportive environments for women with children (e.g. via provision of subsidised childcare facilities or more flexible working hours), so that these women can more feasibly adopt or maintain physical activity. Indeed, these were among women's own suggestions given in response to open-ended questions on what could be done to make physical activity easier for them. On the other hand, women with children saw healthy eating behaviours involving increased fruit and vegetables as being more feasible than did other women. The role of mother may have a positive effect on perceived ability to implement healthy eating behaviours, perhaps due to an increased sense of responsibility among mothers for ensuring healthy food is available in the household for their children.

The present study also showed that overweight women were less likely than other women to see leisure-time activity as being feasible. Public health strategies place an emphasis on increasing levels of physical activity as a means of preventing weight gain and obesity (e.g. references 11 and 30). Given that large proportions of the population in many countries are already overweight or obese, the present findings are a cause for considerable concern. This situation is further compounded by recent evidence showing that young women who are already overweight are at heightened risk of further weight gain $^{2,37}$. This may result in a cycle in which overweight leads to lower levels of physical activity in young women, and this contributes to further weight gain, and so forth. To prevent this, a more detailed exploration of why it is that overweight women do not see physical activity as feasible is warranted. It is likely that embarrassment, lack of confidence and physical discomfort are key factors ${ }^{38}$. These and other issues that may influence overweight women's willingness to be active need to be addressed in future physical activity promotion campaigns, and further research to explore how best to achieve this is required.

Somewhat surprisingly, there were no differences in perceived feasibility of healthy eating or physical activity behaviours between women of different SES. It may be that the education variable used as an indicator of SES in this study was not sufficiently sensitive to detect differences in these perceptions. Women in this age range may not yet have completed their education. Another measure of SES, such as income, may have shown significant associations. Alternatively, women's perceptions of the feasibility of these behaviours may not vary by SES, with other influences (e.g. relating to domestic situation and weight) more important. Established socioeconomic differences in eating and physical activity may 
be mediated by factors other than the perceived feasibility of these behaviours.

This study has some limitations. While the study used a randomly selected, reasonably representative nation-wide sample of young women, the findings reported here might be age- and gender-specific, and not generalisable to other groups. All data were based on self-reported measures. Use of self-reported height and weight may have resulted in underestimation of $\mathrm{BMI}^{39}$; in addition, the self-report feasibility questions were not previously validated. However, the distributions of responses and consistency of the findings with those of studies assessing barriers to healthy behaviours among women ${ }^{34-36}$ suggested that the questions were well-understood and answered honestly.

To our knowledge, this is the first study to explore the feasibility of physical activity guidelines and healthy eating recommendations. The findings thus provide unique information with important implications for health promotion policies and programmes. Results suggest there is a need to revise physical activity promotion messages and/or better inform women as to how they can feasibly adopt the strategies that are being promoted, particularly with regard to physical activity behaviours. While more women reported already following recommended healthy eating advice, better-targeted strategies may succeed in shifting those women who reported these behaviours as feasible towards actually engaging in the behaviours. Messages specifically targeted to women's life stage and circumstances may be more effective in bringing about behaviour change in those groups who perceive these behaviours as difficult. Health promotion strategies addressing perceived time pressures, such as time management training, advice on breaking down physical activity into shorter sessions or lessons in preparing quick healthy meals, may be particularly helpful. Currently there is little evidence of the most effective interventions to prevent weight gain. It is important that future recommendations and interventions take into account the feasibility for individuals to make the kind of behavioural changes that are advocated.

\section{Acknowledgements}

K.B. is supported by a Public Health Postdoctoral Research Fellowship from the National Health and Medical Research Council (ID 136925). D.C. is supported by a Career Development Award funded by the National Health and Medical Research Council and National Heart Foundation of Australia.

\section{References}

1 Williamson DF, Kahn HS, Remington PL, Anda RF. The 10-year incidence of overweight and major weight gain in US adults. Archives of Internal Medicine 1990; 150: $665-72$.

2 Ball K, Brown W, Crawford D. Who does not gain weight?
Prevalence and predictors of weight maintenance in young women. International Journal of Obesity and Related Metabolic Disorders 2002; 26: 1570-8.

3 American Heart Association (AHA). Heart and Stroke Statistical Update. Dallas, TX: AHA, 2002.

4 US Department of Health and Human Services (DHHS). Physical Activity and Health: A Report of the Surgeon General. Atlanta, GA: US DHHS, Centers for Disease Control and Prevention, National Center for Chronic Disease Prevention and Health Promotion, 1996.

5 World Health Organization (WHO). Diet, Nutrition and the Prevention of Chronic Diseases. WHO Technical Report Series No. 797. Geneva: WHO, 1990.

6 Serdula M, Mokdad AH, Williamson DF, Galuska DA, Mendlein JM, Heath GW. Prevalence of attempting weight loss and strategies for controlling weight. Journal of the American Medical Association 1999; 282(14): 1353-8.

7 Australian Bureau of Statistics (ABS). Participation in Sport and Physical Activities. Catalogue No. 4177. Canberra: ABS, 2002.

8 Leslie E, Fotheringham MJ, Owen N, Bauman A. Age-related differences in physical activity levels of young adults. Medicine and Science in Sports and Exercise 2001; 33(2): 255-8.

9 Neilson SJ, Siega-Riz AM, Popkin BM. Trends in energy intake in the US between 1977 and 1996: similar shifts seen across age groups. Obesity Research 2002; 10: 370-8.

10 Jeffery RW, French SA. Epidemic obesity in the United States: are fast foods and television viewing contributing? American Journal of Public Health 1998; 88(2): 277-80.

11 National Health and Medical Research Council. Acting on Australia's Weight: A Strategic Plan for the Prevention of Overweight and Obesity. Canberra: Australian Government Printing Service, 1997.

12 Kellett E, Smith A, Schmerlaib Y. The Australian Guide to Healthy Eating. Canberra: Commonwealth Department of Health and Family Services, 1998.

13 Commonwealth Department of Health and Aged Care. National Physical Activity Guidelines for Australians. Canberra: Commonwealth Department of Health and Aged Care, 1999.

14 Health Education Authority (HEA). Eight Guidelines for a Healthy Diet: A Guide for Nutrition Educators. Abingdon: HEA (in association with the Ministry of Agriculture, Fisheries and Food and the Department of Health), 1997.

15 National Institutes of Health (NIH). Physical Activity and Weight Control. NIH Publication No. 96-4031. Bethesda, MD: NIH, 1996.

16 Crawford D, Ball K. Behavioural determinants of the obesity epidemic. Asia Pacific Journal of Clinical Nutrition 2002; 11(Suppl): S718-21.

17 Krummel DA, Matson Koffman D, Bronner Y, Davis J, Greenlund K, Tessaro I, et al. Cardiovascular health interventions in women: what works? Journal of Women's Health E Gender-Based Medicine 2001; 10(2): 117-36.

18 Wing R. Physical activity in the treatment of the adulthood overweight and obesity: current evidence and research issues. Medicine and Science in Sports and Exercise 1999; 31(Suppl. 11): S547-52.

19 Brown W, Ball K, Powers J. Is life a party for young women? ACHPER Healthy Lifestyles Journal 1998; 45: 21-56.

20 Kahn H, Williamson D, Stevens J. Race and weight change in US women: the roles of socioeconomic and marital status. American Journal of Public Health 1991; 81(3): 319-23.

21 Montero P, Bernis C, Varea C, Arias S. Lifetime dietary change and its relation to increase in weight in Spanish women. International Journal of Obesity and Related Metabolic Disorders 2002; 24: 14-9. 
22 Schafer R, Keith P. Marital stress, psychological distress, and healthful dietary behavior: a longitudinal analysis. Journal of Applied Social Psychology 2000; 30(8): 1639-56.

23 Bray G, Popkin B. Dietary fat intake does affect obesity. American Journal of Clinical Nutrition 1998; 68: 1157-73.

24 Wing R, Klem M. Obesity. In: Gallant S, Keita P, RoyakSchaler R, eds. Health Care for Women: Psychological, Social and Behavioral Influences. Washington, DC: American Psychological Association, 1997.

25 Lynch JW, Kaplan GA, Salonen JT. Why do poor people behave poorly? Variation in adult health behaviors and psychosocial characteristics by stages of the socioeconomic lifecourse. Social Science \& Medicine 1997; 44(6): 809-19.

26 Sobal J, Stunkard AJ. Socioeconomic status and obesity: a review of the literature. Psychological Bulletin 1989; 105(2): $260-75$.

27 Brown W, Bryson L, Dobson A, Lee C, Mishra G, Schofield M. Women's Health Australia: recruitment for a national longitudinal cohort study. Women \& Health 1998; 28(1): 23-40.

28 Bryson L, Strazzari S, Brown W. Shaping families: women, control and contraception. Family Matters 1999; 53: 31-8.

29 Spencer EA, Appleby PN, Davey GK, Key TJ. Validity of selfreported height and weight in 4808 EPIC-Oxford participants. Public Health Nutrition 2002; 5(4): 561-5.

30 World Health Organization (WHO). Obesity: Prevention and Managing the Global Epidemic. Report of a WHO Consultation on Obesity, Geneva, 3-5 June 1997. Geneva: WHO, 1998.

\section{Appendix - Feasibility items}

31 SPSS, Inc.. SPSS for Windows, Release 11.0.0. Chicago, IL: SPSS, Inc., 2001.

32 Tabachnick BG, Fidell LS. Using Multivariate Statistics, 3rd ed. New York: HarperCollins, 1996.

33 Australian Bureau of Statistics (ABS). Australian National Health Survey 2001. Catalogue No. 4364. Canberra: ABS, 2002.

34 Jaffee L, Lutter JM, Rex J, Hawkes C, Bucaccio P. Incentives and barriers to physical activity for working women. American Journal of Health Promotion 1999; 13(4): 215-8.

35 Johnson CA, Corrigan SA, Dubbert PM, Gramling SE. Perceived barriers to exercise and weight control practices in community women. Women \& Health 1990; 16(3/4): $177-91$.

36 Zunft HF, Friebe D, Seppelt B, Widhalm K, de Winter AR, vaz de Almeida MD, et al. Perceived benefits and barriers to physical activity in a nationally representative sample in the European Union. Public Health Nutrition 1999; 2(1a): $153-60$.

37 Ball K, Crawford D, Hodge AM, Ireland P. Patterns and demographic predictors of five-year weight change in a multi-ethnic cohort of men and women in Australia. Public Health Nutrition 2003; 6(3): 269-80.

38 Ball K, Crawford D, Owen N. Too fat to exercise? Obesity as a barrier to physical activity. Australian and New Zealand Journal of Public Health 2000; 24(3): 331-3.

39 Flood V, Webb K, Lazarus R, Pang G. Use of self-report to monitor overweight and obesity in populations: some issues for consideration. Australian and New Zealand Journal of Public Health 2001; 24: 96-9.

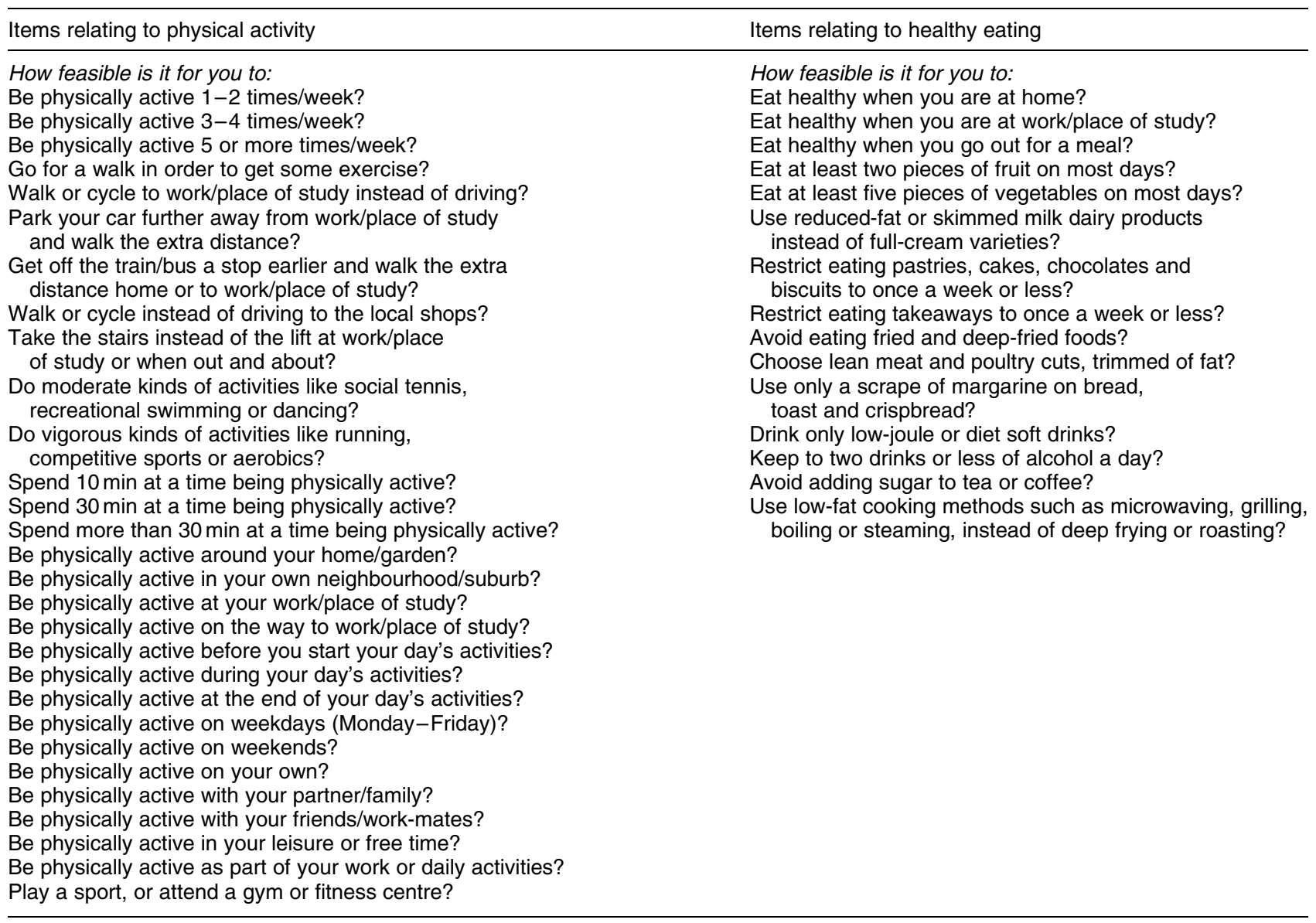

